\title{
Hedges Used in Business Emails: A Corpus Study on the Language Strategy of International Business Communication Online
}

\author{
Siwei Yue ${ }^{1,2} \&$ Xuefei Wang ${ }^{3}$ \\ ${ }^{1}$ Foreign Languages Department, Guangdong University of Education, Guangzhou, China \\ ${ }^{2}$ School of English for International Business, Guangdong University of Foreign Studies, Guangzhou, China \\ ${ }^{3}$ English Department, Guangdong Polytechnic Institute, Guangzhou, China \\ Correspondence: Siwei Yue, Foreign Languages Department, Guangdong University of Education, Guangzhou, \\ 510303, China. E-mail: yue111_2000@126.com
}

Received: April 8, 2014

doi:10.5539/hes.v4n6p49
Accepted: June 11, $2014 \quad$ Online Published: November 19, 2014

URL: http://dx.doi.org/10.5539/hes.v4n6p49

\begin{abstract}
Based on a corpus of 296 authentic business emails produced in computer-mediated business communication from 7 Chinese international trade enterprises, this paper addresses the language strategy applied in CMC (Computer-mediated Communication) by examining the use of hedges. With the emergence of internet, a wider range of hedges are applied extensively in four types of business emails: marketing email, inquiry email, quotation email, follow-up email. Marketing emails have the most hedges while follow-up emails, quotation emails have the least, and inquiry emails in between. As plausible shields, modal verbs are massively adopted in four types of business emails to show politeness and eagerness for business partnership. Marketing emails employ adaptors and rounders to soften the exaggerated expressions in the introduction to the company and its products so as to make a convincing promotion. Both inquiry emails and quotation emails use adaptors and rounders very often when figures concerning products and prices are deliberately offered in a modest way for further negotiation. Follow-up emails use rounders, adaptors and attribute shield extensively in negotiating and reaching agreement. The three types of hedges help both parties to reduce risk and defend themselves against claims with tactic language strategy. The use of hedges in business emails demonstrates the flexibility of business communication with the help of IT technology. The rules of accurate expressions in business letters are no longer strictly observed in computer-mediated communication. The breakthrough of extensive hedge using in business emails showcases a change in business communication manners mediated by IT technology.
\end{abstract}

Keywords: business communication, email, hedge, corpus study, CMC

\section{Introduction}

Electronic Commerce has been widely conducted by international trade companies in the global market these years (Chen, 2007). Thanks to IT advancement, business emails become the most convenient and economical way to make negotiation and business communication in E-Commerce. Business communication online has evolved over time and finally been recognized as a new register, of which the tenor, mode, field are of distinct features in contrast with traditional business communication (Wang, 2012). The trend of using vague language extensively in E-commerce discourse is one feature of them. This new register has been given a variety of definitions by many scholars from different perspectives in their research, thus different terms appear such as electronic discourse (Huang, 2005), internet language (Brown \& Yule, 1983),computer-mediated communication, etc (Crystal, 2001; Renkema, 2004).

As an important type of discourse in E-commerce, business emails have mainly been studied from the perspective of pragmatics such as the politeness principles used in business email writing (Huang, 2012; Xiao, 2011) or genre analysis ( $\mathrm{Li}, 2007 ; \mathrm{Lu}, 2010)$, both of which focus on the macro levels. This research is a further investigation on the hedges used in different types of business emails in response to the author's previous article entitled "On the Trend of Employing Vagueness Rhetoric in E-commerce Discourse-A Case Study of the Use of Hedges in Business Emails" which conducted a contrastive study between traditional business correspondence and business emails based on statistic computing of hedges. Both of them look into lexical and syntax features of business English from the micro level. Based on a corpus of 296 business emails collected from 7 international 
trade companies located in Guangdong province, this paper examines the usage of hedges and their distribution in different types of business emails so as to attach greater importance to the study of lexis and phrases employed in computer-mediated business communication.

\section{The Classification of Hedges and Their Pragmatic Functions in Business Emails}

\subsection{The Definition and Classification of Hedges}

Research on hedges originates from "fuzzy set theory" which was developed by Zadeh in 1965. According to Zadeh (1972), instead of just being in the set or not, an individual is in the set to a certain degree, say some real number between zero and one. In fuzzy logic applications, the non-numeric linguistic variables are often used to facilitate the expression of rules and facts. Since then, an increasing number of scholars have been studying hedges and tried to define them from different perspectives. One of the most well-known definitions was given by George Lakoff. He defines words whose meaning implicitly involves fuzziness, whose job is to make things fuzzier or less fuzzy as hedges (Lakoff, 1973).

Based on previous research on hedges, Xu and He (2012) illustrated the concept of hedge with three functions. First, hedge is a type of meta-language that is used to modify and process fuzzy language. Second, hedge is the linguistic manifestation of the speakers' meta-pragmatic awareness contributing to the efficiency of communication between speaker and hearer on a higher level. Third, hedges are intentionally employed to approximate the objective world with a view to representing preciseness and truthfulness to the highest degree.

Hedges can be categorized into two main types: approximators and shields (He, 1988). Approximators are words or phrases that affect the truth value of the proposition. They could change, rectify the original meaning or set a range for change.

Approximators can be divided into two sub-categories- rounders and adaptors- based on different functions they have. Adaptors can modify the language that is very close to truth value of the proposition. Words and phrases like "sort of", "kind of", "somewhat", "really", "almost", "to some extent" are in this category. Rounders are used to make a zone for adjustment in language, mostly being the modifier of numbers and figures such as "about", "between....and", "roughly".

Shields are fuzzy words or phrases that affect the degree of the speaker's commitment to the true condition of proposition. They can't change the original meaning of language, but make the tone more indirect. There are two types of shields as well-plausible shield and attribute shield. Plausible shields are achieved with modal verbs which can soften the tone and hesitation words which can express a reserved and prudent attitude. Plausible shields include words and phrases like "I think, probably, as far as I can tell, seem, I'm afraid." Attribute shield is manifested in expressions of the third person viewpoint, which means opinions are expressed through a third person. Words and phrases such as "according to...", "presumably", “...says that...", "as is well known", "the possibility would be..." are some of them.

\subsection{The Pragmatic Functions of Hedges Used in Business Emails}

Traditional business English writing can be characterized by features of correctness, clarity, conciseness, concreteness, completeness and courtesy, which are collectively known as $6 \mathrm{C}$ rules of business English writing (Huang, 2012). As one important type of business English writing, business correspondence shares the 6C rules in the way that its language style is formal and the wording is accurate. Accordingly, the use of hedges is not prominent in traditional business correspondence writing as its vagueness and fuzziness should mostly be avoided. But the hedges do appear in business correspondence sometimes in terms of modal verbs which function as plausible shield for it can make the tone of utterance more friendly and polite (Li, 2010). With the development of E-commerce assisted by Internet, emails have become one of the most indispensible channels of business communication. According to Huang (2005), discourse of business emails for international trade is recognized as a new register, for it absorbs some features of oral discourse as well as written discourse. Compared with traditional business correspondence, the discourse of business emails is much more informal, colloquial and individual. Ginenez (2000) believes that the language used in emails is more straightforward and distinctive than in traditional letters when people try to make a request or command. The nature of informality, colloquialism, personality in business emails makes hedges overspread in business emails. Unlike the limited use of hedges in traditional business correspondence, various types of hedges are extensively used in business emails, each of which serves a unique pragmatic function. As one type of plausible shields in hedges, modal verbs are applied in business email to conduct the business communication in a more polite and cooperative manner. Hedges such as rounders and approximators function to specify the description or modify the exactness of language so as to avoid being too subjective or prudent. For business negotiation in emails, the use of hedges can 
work as a language strategy for potential compromise, provided that the business articles are vague and unsettled on purpose.

\section{Research Design}

Business correspondence discourses are usually classified into three types: positive correspondence, neutral correspondence and negative correspondence (Li, 2010). And other scholars try to reclassify them as request correspondence, inquiry correspondence, reply correspondence, complaint correspondence, etc (Xiao, 2011; Huang, 2012). The former classification is too general that the different numbers and distributions in hedge usage among the three types of business correspondences are hard to recognize. And the latter categorization seems not appropriate as well because it is overdone by cutting multi-functional correspondences into segments. Otherwise it cannot be put in any type of correspondence. Consequently, the information flow in a complete correspondence has to be cut into segments and labeled request, inquiry or else. This is really disturbing when recognizing and collecting hedges in research. In this paper, based on previous classification, business emails discussed here are categorized into four types by the topic of each email. They are marketing email, inquiry email, quotation email, and follow-up email. A corpus has been established, consisting of 296 authentic business emails, including 78 marketing emails, 67 inquiry emails, 59 quotation emails and 92 follow-up emails collected from 7 international trade companies in Guangdong province, China. The companies in discussion are all small-to-medium sized enterprises working in manufacturing and selling of knife, food, clothes, hardware, furniture and leather products.

Based on the corpus, hedges of different types will be recognized, collected and examined respectively under each category of business emails. He's (1988) classification of hedges are employed as a framework while specific words and phrases of hedges are listed in the framework, which is illustrated in Table1. Among these words and phrases, part of them come from He's and the rest of them are provided by the author who recognizes them based on the definition of hedges and the unique characteristics of business discourse. As is shown in Table 1, the 296 business emails will be examined to recognize these hedges used and their numbers and distributions in each type of business emails.

Table 1. The classification of hedges and their word list

\begin{tabular}{|c|c|c|c|}
\hline \multirow[b]{2}{*}{ Approximator } & \multicolumn{2}{|l|}{ Adaptor } & $\begin{array}{l}\text { sort of, kind of (kinda), somewhat, really, almost, quite, } \\
\text { entirely, a little bit, little, some, to some extent, more or } \\
\text { less, preferably, better to be... }\end{array}$ \\
\hline & \multicolumn{2}{|l|}{ Rounder } & $\begin{array}{l}\text { Approximately, essentially, about, something } \\
\text { between... and..., over, up to, or else, or up...to..., one of } \\
\text { the..., around, more than, minimum, maximum, no more } \\
\text { than, less than... }\end{array}$ \\
\hline \multirow{3}{*}{ Shield } & \multirow[b]{2}{*}{ Plausible } & $\begin{array}{l}\text { Modal } \\
\text { verb }\end{array}$ & $\begin{array}{l}\text { would, could, might, may, would like, had better, should } \\
\text { you..., if I were you, }\end{array}$ \\
\hline & & $\begin{array}{l}\text { Hesitation } \\
\text { word }\end{array}$ & $\begin{array}{l}\text { I think, probably, as far as I can tell, as far as I'm } \\
\text { concerned, seem, wonder, I am (was) wondering, I } \\
\text { suppose, I assume, I'm afraid, I believe, hard to say }\end{array}$ \\
\hline & Attribute & $\begin{array}{l}\text { The third } \\
\text { person } \\
\text { viewpoint }\end{array}$ & $\begin{array}{l}\text { according to someone, presumably, someone says that..., } \\
\text { as is well known, the possibility would be..., the } \\
\text { probability is..., generally estimated }\end{array}$ \\
\hline
\end{tabular}

\section{Results and Discussion}

\subsection{The Overall Description of Hedges in Business Emails}

After 296 business emails are examined in verbatim, 68 out of 78 marketing emails use hedges (87.5\%). 50 out of 67 quotation emails use hedges (74.5\%), 27 out of 59 quotation emails use hedges (47.4\%). 46 out of 92 follow-up emails use hedges (50\%). More than half of business emails of each type use hedges. Marketing emails and inquiry emails use hedges most often, both of which exceed $70 \%$. Despite quotation emails with the least odds, they are close to $50 \%$. In summary, in contrast with the rare of hedges used in traditional business correspondence, hedges are prominently used in various business emails, with marketing emails ranking the first, inquiry email the second, quotation email and follow-up email the last. 
There is discrimination among four types of business emails concerning the frequency of hedge use, which is determined by the intention of each type of business emails. Marketing emails aim to promote the company to potential foreign clients. To establish a good image of the company, hedges are used to make the language more polite and friendly in introduction to the company and its products. The function of hedges used in marketing emails is either to make a polite tone or modify the description to be more objective, convinced and reader-friendly. Thus, marketing emails employ hedges the most. In inquiry emails, the author represents the party which is interested in the products in discussion. The intention of inquiry email writing is to inquire as much information as possible to know more about the products such as the design of product, size, and price. Since the inquiry happens between the seller who knows more about the product and the potential buyer who knows little about it, the disparity of information makes the inquirer are bound to use vague language to initiate the communication so as to explore more useful information they can hopefully get from the seller. In vague inquiry, hedges are frequently applied in terms of rounders and adaptors. The intentions of marketing emails and inquiry emails lead to the massive use of hedges.

Quotation emails are written to inform inquirers of information that is asked about the product, mainly the price. As the most essential information in trade, price of the product should be put in an accurate way. No ambiguous, changeable expressions should be used when the price is fixed. Otherwise, any misleading by vague language in quotation emails can lose a business opportunity or even damage a valuable transaction. So in quotation emails, hedges only appear in terms of modal verbs which are used to soften the tone in conformity with politeness principle in business communication. That is why hedges in quotation emails are not as many as marketing emails and inquiry emails but still hold some share around $50 \%$.

Follow-up emails here are defined as the business emails that are produced to make the transaction smooth from the moment that intents are reached until the business is closed. In follow-up emails, negotiations are made for issues that have not settled yet, business disputes, or clarification of unclear information. Based on these intentions, hedges used in follow-up emails are restricted to modal verbs which only serve to make a friendly tone. This is especially indispensible in negotiations when two parties are arguing with sensitive nerves. A hostile tone can easily trigger the anger of the other party. Staying polite and friendly in arguing over disputes can be achieved by using modal verbs to sound positive. But no rounders, adaptors and other types of hedges are welcome here for clarification of important information. Accordingly, there is a sharp reduction to numbers of hedges used in follow-up emails.

\subsection{The Distribution of Different Hedge Types in Business Emails}

To further discuss the distribution of different types of hedges used in business emails, this paper selects 191 emails that have used hedges from 296 business emails in this corpus. There are 68 marketing emails, 50 inquiry emails, 27 quotation emails and 46 follow-up emails. Different types of hedges are calculated respectively under four categories of business emails: marketing emails, inquiry emails, quotation emails and follow-up emails. 191 business emails are examined so as to identify the words and phrases of different hedge types that are listed in Table 1. Based on the data collected, hedges that appear in business emails are elaborated in terms of numbers, types, percentage in Table 2.

Table 2. The use of hedges in different types of business emails

\begin{tabular}{c|c|c|cccc}
\hline \multicolumn{2}{c|}{ Hedges } & Marketing & Inquiry & Quotation & Follow-up \\
\hline \multirow{2}{*}{ Approximator } & \multicolumn{2}{|c|}{ Adaptor } & $19(10.9 \%)$ & $35(33.0 \%)$ & $9(17.7 \%)$ & $32(28.0 \%)$ \\
\cline { 2 - 3 } Shield & \multicolumn{2}{|c|}{ Rounder } & $87(50 \%)$ & $25(23.6 \%)$ & $12(23.5 \%)$ & $27(23.7 \%)$ \\
& \multirow{2}{*}{ Plausible } & $\begin{array}{c}\text { Modal } \\
\text { verbs }\end{array}$ & $58(33.4 \%)$ & $36(34.0 \%)$ & $27(53.0 \%)$ & $42(36.9 \%)$ \\
\cline { 2 - 3 } & $\begin{array}{c}\text { Hesitation } \\
\text { word }\end{array}$ & $9(5.1 \%)$ & $8(7.5 \%)$ & $3(5.8 \%)$ & $4(3.5 \%)$ \\
\cline { 2 - 3 } & Attribute & $\begin{array}{c}\text { The third } \\
\text { person } \\
\text { viewpoint }\end{array}$ & $1(0.6 \%)$ & $2(1.9 \%)$ & $0(0.0 \%)$ & $9(7.9 \%)$ \\
\hline & total & $174(100 \%)$ & $106(100 \%)$ & $51(100 \%)$ & $114(100 \%)$ \\
\hline
\end{tabular}


As is shown in Table 2, modal verbs that function as plausible shield are extensively used in all four types of business emails in a large proportion. According to He (1988), modal verbs are used as hedges to express one's estimate of something uncertain or to soften the tone of language in a polite and friendly way. Under each type of business emails, modal verbs take the largest share of hedge distribution except for marketing emails in which modal verbs follow rounders in proportion of hedge distribution. Hesitation words as plausible shield are rarely adopted in all four types of business emails. The third person viewpoint hedges are the least, with less than $2 \%$ in marketing email and inquiry email, 0 in quotation emails. The distribution of approximators in inquiry emails, quotation emails, and follow-up emails is similarly in between. But it is noticeable that the numbers of rounders used in marketing emails are much more than any other types, accounting for half of all types of hedge while adaptors shrink to around $10 \%$.

In a word, business emails heavily employ two types of hedges: modal verbs used as plausible shield and approximators which consist of rounders and adapters. The third person viewpoint as attribute shield is seldom used in business emails except one or two accidentally appear in follow-up emails. Sharing the same category of plausible shield, modal verbs is dominant over all categories of hedges in business emails while hesitation words are hard to encounter in business emails.

\subsection{The Pragmatic Functions of Hedges in Different Types of Business Emails}

To explore the unique pragmatic functions of each category of hedges used in business emails, this paper intends to examine various hedges in the context of different type of business emails. By computing the number of each type of hedges used under each business email category (See Table 3), the research suggests that marketing emails, inquiry emails, quotation emails and follow-up emails tend to be distinct in a way that the ranking of each type of hedges in each category is different from others,.

Table 3. The sequence of hedge categories in four types of business emails

\begin{tabular}{c|ccccc}
\hline Sequence & 1 & 2 & 3 & 4 & 5 \\
\hline Marketing & rounder & modal verb & adaptor & hesitation word & $\begin{array}{c}\text { The third person } \\
\text { viewpoint } \\
\text { Inquiry }\end{array}$ \\
Quotation & modal verb & adaptor & rounder & hesitation word & $\begin{array}{c}\text { Then } \\
\text { viewpoint }\end{array}$ \\
Follow-up & modal verb & rounder & rounder & Hesitation word & $\begin{array}{c}\text { The third person } \\
\text { viewpoint } \\
\text { hesitation word }\end{array}$ \\
\hline
\end{tabular}

This can be explained by the fact that each category of business emails with its unique intention has to adopt the most fitted matrix of hedges, considering that each type of hedges holds distinctive pragmatic functions in business communication.

Marketing emails consist of an introduction to the company and to its products. The information delivered in marketing emails aims to make the company sound more powerful and competitive, the products more desirable in quality, design and so on in order to attract potential clients. To achieve this, overstated description is frequently made about the company's history, capacity, operating experience, market or the products' variety, quality in marketing emails. The use of rounders in marketing emails sets an acceptable range of adjustment in figures, thus helps to modify the facts with vagueness. The overstatement in figures of business information in marketing emails maintains the truthfulness due to the proper employment of rounders, otherwise they will be regarded as fake facts.

Examples:

(1) *** delivers more ground packages than any other carrier.

(2) Our factory is specializing in producing different kinds of heat press machines for over 12 years experience.

(3) Our main markets are France, Benelux, Switzerland, Italy and Spain and mostly sell to the supermarkets like Fanc, Darty, Wal-mart, etc.

The three sentences above are picked from three marketing emails for different companies. All of them use 
rounders. In (1), rounder "more...than" helps the company to make comparison with other competitors so as to show its outstanding capacity. In (2), rounder "over" modifies the fact "12 years". In this way, readers are impressed by the long history of the company. In (3), "mostly" is applied to emphasize the overspreading markets the company occupies. These examples illustrate that rounders are used the most in marketing emails for their vagueness in expression can offset or at least reduce the negative effect of being boastful in promoting the company and products. Exaggerated description of the company and its products modified by rounders make it impressive and reliable. Therefore, rounders take the largest share in distribution of hedges used in marketing emails, followed by modal verbs which can make the tone polite.

Unlike the overstated description of the company and products in marketing emails, inquiry emails are employed to initiate business communication at the tentative stage. On the one hand, maintenance of good will and friendly atmosphere is a must in inquiry emails. On the other hand, the inquiry of product information and price is the focus as well.

Modal verbs can be used to soften the tone of speaker, so as to follow the principle of politeness (He Ziran, 1988). This function works very well in inquiry emails such as:

Examples:

(4) If you could quote us with a price and a time for the product to be manufactured and delivered, that would be great.

(5) I would like to ask a good price and delivery time for the next item: ...

About inquiry on product and price, rounders and adaptors are used on most occasions when inquirers can just provide a general idea of what he wants to know in vague language. This is the usual practice because inquirers can hardly specify the items and conditions they are interested in, considering they know very little about the seller and its products.

Examples:

(6) Could you let me know your company have what kind of mobile battery's shape, size, weight, reserve, capacity, price and so on.

(7) I would ask about your offer if I need buy 100pcs power bank charger 5200 mah or up.

(8) We have requirement some 1,000 pcs of above item.

(9) bWe are looking for power bank in qty: 1000ps with $5000 \mathrm{mah}$, target size is around $87 * 55 * 20 \mathrm{~mm}$, pls send me the photo and quote if any, thanks.

Sentence 6 lists all the items that concern the inquirer - shape, size, weight, reserve, capacity, price, all of which interest the inquirers the most. But just in case of missing any other aspects that are not mentioned but very important, the author uses the rounder "so on" to extend the items at request. If there is some other information to supplement, the seller is also allowed to add them up because of the rounder "so on".

Sentences 7-9 all apply approximators to describe the features of products in question based on the inquirer's ambiguous picturing of the products he is interested in. To be specific, in sentence 8 , the adaptor "some" works as the modifier of the figure " $1000 \mathrm{pcs}$ " to widen the acceptable range of the product's quality. In sentence 7 and 9, rounders "or up" and "around" are employed to extend the range in the products' size and capacity at request.

In brief, modal verbs as plausible shield are used the most in inquiry emails, followed by approximators, the former of which helps the writing be polite while the latter of which makes the inquiry email be as much informative as possible.

Quotation emails employ modal verbs as plausible shields like inquiry emails in large quantities. The use of this type of hedges is more frequently than any other types in quotation emails. This is exactly in accordance with the fact that language used in quotation emails are mostly accurate and specific, avoiding ambiguity in price or any other important information concerning the products. Apart from modal verbs which are used to soften the tone, other types of hedges all adapt the meaning in some way. Thus quotation emails avoid hedges to the minimum. Only rounders are used indicating the range of price occasionally.

Examples:

(5) If you have, we'd like to send your order to the place you suggest in China.

(6) *The enclosure are the packing design, you may choose.

(7) *And if you want to shipping by sea, it will also cost you about US $\$ 250$ on customs clearance in your 
country, excluding the freight that we send to you.

(Note: Language fallacies are reserved to record the originality of business emails, labeled by *)

Sentences 5 and 6 are examples that apply modal verbs as plausible shield. Sentence 7 adopts the rounder "about" to modify the price information "US $\$ 250$ " because the price here is just an estimate. The employment of rounders helps to leave some space for further discussion.

In follow-up emails, modal verbs dominate the use of hedges. When a proposal or a request is made, the language in communication should be polite and friendly instead of being rude. Thus most directions are made in terms of requests or inquiries with the hedges "would", "could", or "might".

For example:

(8) We hope you could pay part of the UPS freight fee.

(9) If they can't produce the candy this week, we may have to buy October-made candy.

(10) We would like to receive your PO and work with you.

(11) Could you pls tell us how many films do you need?

In addition, other types of hedges are used in follow-up emails to defend the author against claims or business disputes in negotiation with follow-up emails. Hedges are considered as an effective language strategy to reduce risk and find excuses to avoid taking responsibility for business loss. For instance, phrases of the third person viewpoint are used to detach the author's ideas from the statements made in the email. If statements made in emails are inconsistent with the outcome, and the business dispute occurs afterwards, the author is free from being blamed by indicating the statements are made based on the third person viewpoint both agreed on. The third person viewpoint creates an objective perspective towards the business issue. Partners can easily trace back to the third person viewpoint, but not either side's standpoint.

For example:

(12) Generally estimated, it will be sent on Saturday.

(13) According to the revised drawing, they have to open tool for small tube...

Rounders and adaptors are also resorted to when the author refers to the key information of dispute to justify himself. There's one sentence taken from one follow-up email, namely, a complaint email.

\section{(14) ALMOST 4 MONTHS HAVE PASSED AND I HAVE TO TELL MY CLIENT.}

This email uses capital letters throughout the whole discourse. It is obvious that the author is very angry about the delay of goods delivery. In the email, the buyer blames the seller for not delivering goods on time. To emphasize the fact that the goods have been delayed for extremely long time, the author uses adaptor "almost" to modify the figure " 4 months". "almost 4 months" is much stronger than "more than 3 months" in tone. The intensified impression that the goods have been delayed too long is easily established by the employment of adopters. Consequently, the intention to place blame on the author's counterpart is achieved in this follow-up email.

In response to complaint emails, the blamed party tries to explain the issue with ambiguous statement when he is the one that is destined to take responsibility for the loss. Approximators are applied a lot as language strategy to interpret the dispute issue in his favor. Hopefully, the blame could be abated to some extent.

The extract below is the reply email to the complaint above about the goods delay.

(15) When you came to China this May, you bought some products for your clients and my colleague XX arranged the purchasing and shipment for you. Almost all the products were ready by the beginning of June and we were about to ship the cargo to Chile. But one of your suppliers delayed the delivery time, so only until the end of July, we got the last merchandise... But unfortunately, there was some problem of the declaration through the customs and it was detained.

The adaptor "some" modifies "problem" to generalize the reference. Thus the focus of the problem itself is faded out. Instead, the author uses "almost" to show that he is very efficient in collecting all products, which is a strong defense for his being innocent. Moreover, he uses rounder "one of..." to transfer the responsibility to the third party which is not indicated clearly.

In summary, modal verbs are overwhelming in all types of business emails in order to implement the politeness principle in business communication. Approximators appear to modify the exaggerated expressions in promotion of the company and its products. Besides, in follow-up emails, a wise use of approximators is a language strategy 
to escape from blame on business disputes or losses. With different situations, rounders and adaptors are applied to make the statement favorable for the author whether he is the one to blame or to be blamed. Hedges of the third person viewpoint are not so commonly adopted in marketing emails, inquiry emails and quotation emails. However, in follow-up emails, words and phrases of the third person viewpoint assist the author in avoiding making subjective statement that results in a business failure or damage.

\section{Conclusion}

Hedges are frequently used in business email writing. According to the proportion of business emails that contain hedges in language, marketing emails take the largest share while negotiation emails take the smallest. Inquiry emails and quotation emails are in between. Traditional business correspondence uses hedges only in ways that modal verbs are considered as softeners to make the tone of writing more polite and friendly. In contrast, business emails use diverse types of hedges in a large quantity, of which adaptors and rounders are employed on regular basis along with modal verbs. Like traditional business correspondence, modal verbs as hedges are massively applied in business emails as the language strategy to show the author's cooperative attitude and good will to the receiver. In marketing emails, adaptors and rounders mostly work as modifiers to beautify the description about products and introduction to the company, eventually to promote products and to set good reputation for the company. In inquiry emails and quotation emails, adapters and rounders are deliberately used to make some important business information such as the size, quantity, price of products unsettled. This helps to leave some space for compromise in further negotiation. Follow-up emails employ adaptors, rounders and the third person viewpoint shields to defend the author, for the vagueness strategy in language helps to reduce responsibility and financial risk on condition of business dispute. In the era of E-commerce, business email writing seems to be the prioritized choice for business communication, boasting for its swiftness and cost-effectiveness. International business partners turn to be more adaptive in order to reach agreement or reduce risk. With the emergence of this new register, it has become a must to better understand the linguistic features of business email discourses and the pragmatic functions they have. A good mastery of their characteristics and functions can help develop effective language strategies in computer-mediated business communication based on different business goals in different situations. This paper has just moved one step towards it by examining hedge usage and its functions in an authentic business email corpus. Hopefully, there will be more related studies to come in response to this research, which can jointly shed light on business email discourse studies.

\section{References}

Brown, G., \& Yule, G. (1983). Discourse analysis. Cambridge: Cambridge University Press. http://dx.doi.org/10.1017/CBO9780511805226

Chen, S. Y. (2007). How do international trade enterprises explore global markets with business emails? Market Modernization, 10, 88-90. http://dx.doi.org/10.3969/j.issn.1006-3102.2007.28.054

Crystal, D. (2001). Language and the internet. Cambridge: Cambridge University Press. http://dx.doi.org/10.1017/CBO9781139164771

Ginenez, J. C. (2000). Business email communication-Some emerging tendencies in register. English for Specific Purposes, 3, 237-251. http://dx.doi.org/10.1016/S0889-4906(98)00030-1

He, Z. R. (1988). A survey of pragmatics. Changsha: Hunan Education Press.

Huang, G. W. (2005). Characteristics of electronic discourse. Foreign Languages and Their Teaching, 12, 1-5. http://dx.doi.org/10.3969/j.issn.1004-6038.2005.12.001

Huang, L. L. (2012). Politeness in business emails of complaint and reply-A case study on business emails of a shoe manufacturer in Fuzhou city. Journal of Southwest Agricultural University (Social Science Edition), 6, 90-95.

Lakoff, G. (1972). Hedges: A study in meaning criteria and the logic of fuzzy concept. In P. Peranteau, J. Levi, \& G. Phares (Eds.), Papers from the Eight Regional Meeting. Chicago Linguistic Society.

Li, J. R. (2007). Genre analysis of English business emails. Foreign Languages and Their Teaching, 7, 21-25. http://dx.doi.org/10.3969/j.issn.1004-6038.2007.07.007

Li, L. (2008). Textual features of business emails and teaching English for business correspondence. Journal of Zhejiang University of Technology (Social Science), 2, 237-240.

Li, Y. H. (2010). A survey and analysis of business correspondence. Journal of Anhui University of Science and Technology (Social Science), 1, 78-82. http://dx.doi.org/10.3969/j.issn.1672-1101.2010.01.019 
Lu, D. (2010). The application of genre analysis in English business emails. Journal of Inner Mongolia $\begin{array}{lllll}\text { Agricultural University } & \text { (Social Science } & \text { Edition), } & 2, & 376-378 .\end{array}$ http://dx.doi.org/10.3969/j.issn.1009-4458.2010.02.154

Renkema, J. (2004). Introduction to discourse studies. Amsterdam: Benjamins. http://dx.doi.org/10.1075/z.124

Wang, S. L. (2012). The change of studies of intercultural business communication in cyberspace. Academic Exchange, 2, 134-137. http://dx.doi.org/ 10.3969/j.issn.1000-8284.2012.02.033

Xiao, Y. P. (2011). The pragmatic study of requesting strategies used in international business emails. Foreign Language Education, 6, 33-37.

Xu, Z. H., \& He, Z. R. (2012). A functional analysis of the de-fuzzification of linguistic hedges. Contemporary Foreign Languages Studies, 7, 29-32, 37.

Zadeh, L. A. (1972). A fuzzy-set-theoretical interpretation of linguistic hedges. Journal of Cybernetics, 3, 4-34. http://dx.doi.org/10.1080/01969727208542910

\section{Copyrights}

Copyright for this article is retained by the author(s), with first publication rights granted to the journal.

This is an open-access article distributed under the terms and conditions of the Creative Commons Attribution license (http://creativecommons.org/licenses/by/3.0/). 